\title{
MANAGEMENT OF COMPLETE TRACHEAL RUPTURE FOLLOWING BLUNT TRAUMA
}

\author{
Mahesha Dabare ${ }^{1^{*}}$, Hemantha Perera ${ }^{2}$ \\ Registrar, Anaesthetics, National Hospital of Sri Lankal, Consultant Anaesthetist, \\ Cardiothoracic unit, National Hospital Sri Lanka ${ }^{2}$ \\ *Corresponding author E-mail: mahesha.seneviratne@gmail.com
}

Key Words: Blunt tracheal trauma, Airway injury, Bronchoscopy assessment in airway trauma.

The patient was a 33-year-old, heavily built male. He was employed as a manual labourer in a container yard where the accident took place. His upper chest was crushed between the back of a container carrier and an engine. He didn't suffer any external injuries but realised it was difficult to breath and he coughed out some blood as well. He came to the accident and emergency unit within 20 minutes of the accident. On initial assessment patient had dyspnoea and a respiratory rate of $18 / \mathrm{min}$. The oxygen saturation on air was $93 \%$. Subcutaneous surgical emphysema was evident in the upper chest. There were no lung signs. He was haemodynamically stable and GCS was 15/15 although the speech was diminished to almost a whisper. A hard cervical collar was applied to the neck. 21 of oxygen was given via mask and it increased the saturation to $98 \%$. The AP chest radiograph revealed subcutaneous and mediastinal emphysema and left first rib fracture. Cervical spine $\mathrm{x}$ rays were normal. He was admitted to the accident service ICU for monitoring. The $\mathrm{paO}_{2}$ was $85 \mathrm{mmg}$ and $\mathrm{paCO}_{2}$ was $40 \mathrm{mmHg}$ in the initial arterial blood gas.

Emergency flexible bronchoscopy was arranged in the ENT theatre. Only up to the vocal cords were visualized because a soft tissue mass was seen obstructing the airway beyond that point. An emergency tracheostomy under local anaesthesia was planned. During the soft tissue dissection an air gushing defect was discovered $1 \mathrm{~cm}$ below the supra sternal notch. A $7.0 \mathrm{~mm}$ ETT was inserted through the deficiency after splashing $1 \%$ lignocaine $2 \mathrm{ml}$. ETT was attached to a T piece and patient was allowed spontaneous breathing. Sedation was given with midazolam to tolerate the ETT. Patient continued to maintain $96 \%$ oxygen saturation with $50 \%$ inspired oxygen. Urgent ultra sound scan of the thorax was done but it was inconclusive due to emphysema. Contrast CT scan of the thorax and abdomen concluded possible damage to the supraglottic region. Thoracic surgical team planned a midline sternotomy with the availability of the cardiopulmonary bypass.

\section{Perioperative management}

Invasive lines were avoided in the neck. Right radial arterial line and a left femoral CVP catheter were inserted under local anaesthesia. After ETT suction patient was induced with IV fentanyl and thiopentone sodium. Anaesthesia was maintained with isoflurane and patient was allowed to breathe spontaneously. Pancuronium was given and IPPV commenced only after sternotomy.

Total circumferential disruption of the trachea was found just below the thyroid isthmus. The ETT was removed and the distal half of trachea was reintubated across the operative field under aseptic conditions by the surgeon with a $7.5 \mathrm{~mm}$ ID reinforced ETT. Ventilation was continued through the distal tracheal portion. Through and through sutures were applied to the free tracheal ends. Before approximating the tracheal sutures, the reinforced ETT was removed and an orotracheal tube was advanced in to the distal portion. The cuff was positioned below the level 
of the tear and above the carina. Secretions in the airway were a problem reducing the saturation from time to time and regular gentle suction was necessary.

The patient was transferred to the cardiothoracic ICU for observation and support. The neck was kept flexed by a suture in order to aid tracheal healing. The ETT level and cuff pressures were frequently checked and the latter was kept below $20 \mathrm{cmH}_{2} \mathrm{O}$. Adequate analgesia was provided with morphine and sedation with a propofol infusion to avoid sudden neck movements. Frequent blockage of the tube with thick secretion was a major problem during the post operative period. Bronchoscopic suction was necessary to clear the thick secretions in the ETT. He was extubated on post operative day two and was discharged to the ward on post operative day 4. A flexible fiberoptic bronchoscopy was done as an out patient two weeks later to assess the trachea for proper granulation and healing suture lines.

\section{Discussion}

Tracheal injury due to blunt chest trauma is a rare occurrence with an incidence of $<1 \%$. However, it remains dubious how many patients with tracheobronchial injury are treated because, grave accidents cause deaths directly before precise diagnosis. Tracheal rupture has a reported mortality of $20-50 \%$ and a morbidity of $10-25 \%$. Majority of the tracheo-bronchial tears can be found within $2.5 \mathrm{~cm}$ distance to the carina.

The possible mechanism of injury in the discussed case could be sudden increase in intra tracheal pressure due to compression of the upper chest with a closed glottis or a crush injury to the airway as it is compressed against the vertebral bodies. The presentation can be insidious. In complete transection supporting tissues may hold the damaged area together, providing an airway which is adequate to reach the hospital as in the discussed case. The diagnosis can be easily missed because the patient may not have any visible external injuries. Pneumothorax is usually associated with bronchial injury but not isolated tracheal trauma. Patient is haemodynamically stable in the absence of major vessel injury. So airway injury should be suspected in patients presenting with the triad of dyspnoea, haemoptysis and mediastinal emphysema. Mediastinal emphysema may indicate both tracheo bronchial or oesophageal injury unless proven otherwise. Failure to recognize the injury, results in progressive airway obstruction, atelectasis and suppuration.

'Saving life' is dependent on early securing of the air way. The airway management strategy should be carefully planned because total disruption of airway can occur with attempts of tracheal intubation. Therefore spontaneously breathing patients should be observed for the adequacy of airway in an ICU or HDU until the severity is determined with investigations and a well equipped theatre and experienced personnel are available. According to recent literature early bronchoscopy is of great help in diagnosing the injury and to help in securing the airway. Our patient's bronchoscopy view was obscured with blood and tissue therefore tracheostomy had to be considered. But if the injury is in the lower trachea even tracheostomy may not prove effective. But a patient breathing spontaneously may be able to maintain his/her airway with the soft tissue supports around the airway. Therefore spontaneous respiration should be maintained as done in our patient until the time of direct access to the airway after sternotomy. The airway repair surgery should be planned early in tracheal and major bronchial injury but conservative management is preferred in peripheral airway injury. Airway management during the surgery needed close co operation between the surgeon and the anaesthetist. High frequency jet ventilation has been used in some countries successfully in order to facilitate tracheo-bronchial repair.

Post operatively many practice extubation at the end of the surgery. We planned extubation on post operative day two. The flexion at the neck was maintained to minimize traction on the suture lines. Accumulation of airway secretion is a common problem due to depressed cough reflex and denervation injury. Gentle suction should be done in order to minimize mechanical injury to the anastomosis by the catheter tip. Bronchoscopic guided aspiration is indicated to clear secretions in extubated patients. A post operative bronchoscopy was done in two weeks and it showed the granulations at the healing tracheal site. 
Tracheo-bronchial injury is a rare occurrence and the diagnosis can be difficult. Early diagnosis in the emergency department is imperative in saving the life. Observation made by the anaesthetist during fibreoptic intubation is important for early diagnosis and airway management. Therefore the need for anaesthetist training and making facilities available in the emergency department in this regard is important.

\section{References}

1. Kelly JP, Webb WR, Moulder PV et al: Management of air way trauma: Tracheobronchial injuries. Annals of Thorac Surg. 1985 40:551-555
2. Masao Tomita et al, Surgery for Traumatic Injury of the Trachea and Bronchus, Acta Med. Nagasaki 38:293 - 295

3. Jane Huang MD et al Unsuspected tracheal rupture in blunt thoracic trauma CAN J ANAESTH 1994 / 41: 12 / pp 1208-10

4. Tracheostomy and tracheal reconstruction, Kaplan Thoracic anaesthesia 4th edition

5. Dreyfuss D, Jackson RS, Coffin LH et al: High frequency ventilation in the management of tracheal trauma. J Trauma 1986 26:287-289

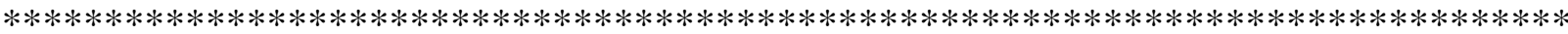

\section{THE COLLEGE OF ANAESTHESIOLOGISTS OF SRI LANKA}

\section{FREE PAPERS:}

The rules of the competition are:

1. Open to all medical practitioners in Anaesthesia.

2. Duration of the presentation must be no longer than 15 minutes.

3. The work in whole or in part should not have been presented or published elsewhere.

4. An abstract of not more than 200 words should be submitted before the closing date.

5. The first right of publication of the entries submitted lies with the editor of the College of Aanesthesiologists of Sri Lanka.

6. The decision of the panel of judges in all matters relating to the competition including questions relating to eligibility shall be final.

7. The prize will not be awarded if the Judges decide the presentation is not up to standard.

The closing date for the 2011 competition is $\mathbf{3 1}{ }^{\text {st }}$ October 2010. The abstract should reach the undersigned before the closing date. Any expenditure incurred in the preparation of the slides for papers that were selected for presentation will be reimbursed by the College. 3 copies of the full text should be submitted on or before $31^{\text {st }}$ October 2010 to the anaesthetic office. 